ITHAKA S+R

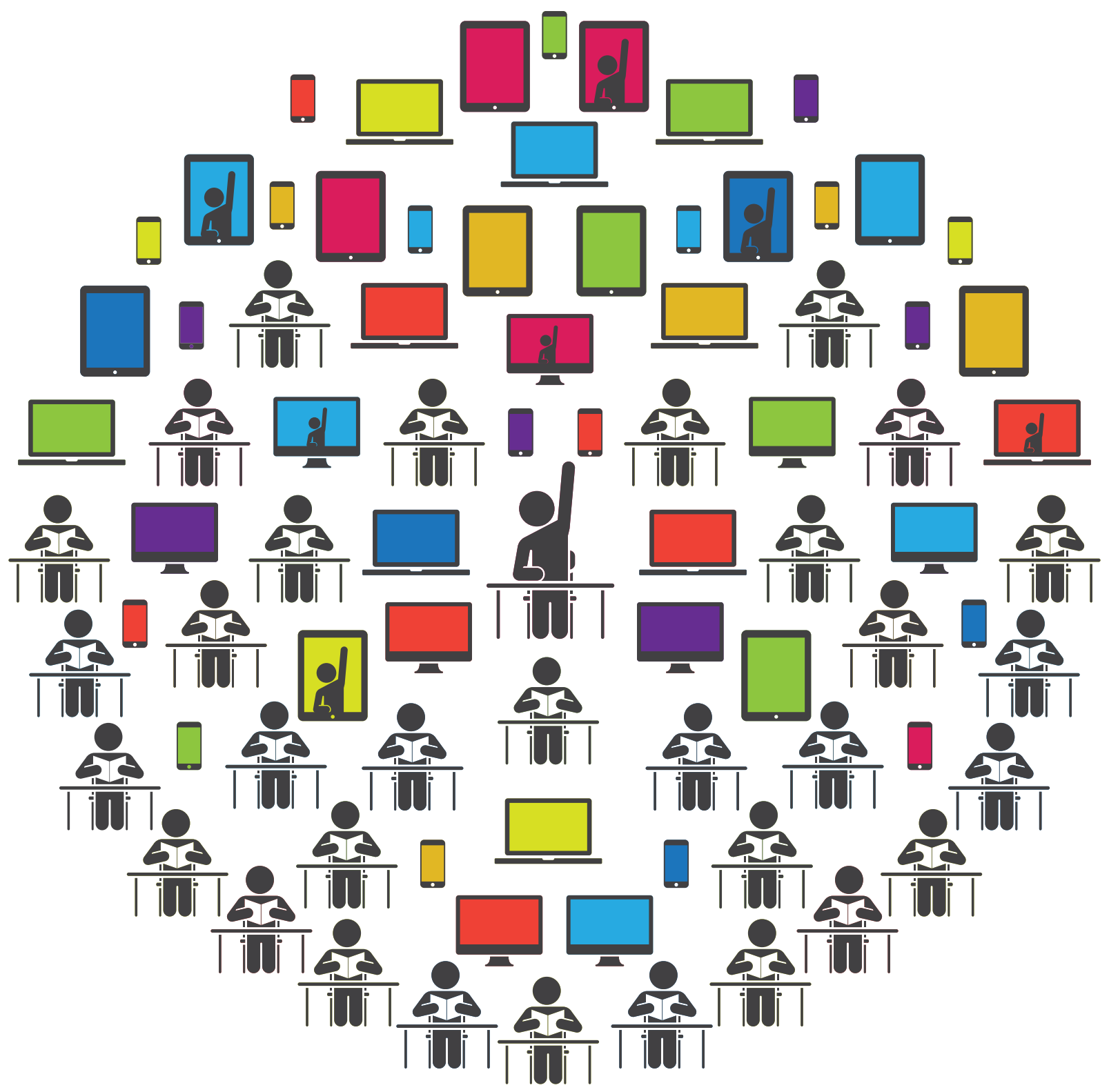

\title{
MOOCs IN THE CLASSROOM?
}

REBECCA GRIFFITHS 


\section{MOOCS IN THE CLASSROOM?}

What would it

look like to embed

M00Cs in a campus

environment other

than the one in

which they were

created?

How would MOOCs

compare with other

online resources and

what role might they

play in the evolving

online learning

marketplace?
The first MOOCs offered by platforms such as Coursera, edX, and Udacity were designed primarily to address one particular goal - to offer courses from faculty at elite institutions to massive communities of students for free. Based on early data, this opportunity was most compelling to two types of students - those in other countries, some of whom lacked access to formal education, and those who were already college-educated and pursued MOOCs in order to gain personal enrichment or enhance their professional skills. ${ }^{1}$ These early MOOC offerings spawned scores of inspiring anecdotes about their impact on students and impressed the public with a new sense of ways that technology might transform higher education.

But there was little evidence to show how MOOCs in their original incarnation could address a central challenge facing our country - producing more college graduates at reasonable cost to students and to the public. A series of questions seemed to demand urgent attention: under what circumstances could students take MOOCs for credit, when even the institutions offering them did not regard them as a substitute for their own classroom-based instruction? What personal support and facilitation would be required for mainstream or academically at-risk college students to benefit from these resources? What would it look like to embed MOOCs in a campus environment other than the one in which they were created? How would students feel about these experiences? How would MOOCs compare with other online resources and what role might they play in the evolving online learning marketplace?

To answer these questions, we embarked on a study of MOOCs used in ways that differ substantially from their original purpose. ${ }^{2}$ Working jointly with the University System of Maryland (USM) and with funding from the Bill and Melinda Gates Foundation, we are testing the hypothesis that MOOCs can be used to improve outcomes and/or reduce costs for students enrolled in traditional institutions. The project began this year, and has had an encouraging start. We succeeded in recruiting faculty members to undertake fifteen tests involving MOOCs, and in gaining permission from Coursera and its partners to use their content in these tests. (We engaged in discussions with edX and Udacity as well, but we were unable to reach agreement on particular test cases.) These participants deserve enormous credit for stepping forward to take part in this initiative, which we hope will add a substantial amount of data to conversations about what role MOOCs should play in higher education. None of this work would be possible without the collaboration of the USM staff and faculty members.

There are a number of ways in which MOOCs might be incorporated into degree programs: students could earn credit for taking MOOCs independently; courses could be created around publicly-offered MOOCs with some local facilitation; institutions could license MOOCs for local delivery, again with some facilitation; or, MOOC content could be blended into hybrid courses. Our tests mostly fit in the last model, though we are conducting one test in which students are enrolling in a "live" MOOC and meet with a local instructor once per week. In most cases, however, our tests bear little direct relation to the original format of MOOCs and are poorly described by the MOOC acronym itself, being neither massive, nor open, nor entirely online. 


\section{There is a growing}

body of evidence

\section{suggesting that}

hybrid formats

have the potential

to improve student

\section{outcomes and}

reduce costs.
Why have we taken this approach? There are some practical problems with designing an assessment of MOOC students "in the wild," but even more importantly, we believe that mainstream college students require the personal support and interaction that traditional institutions are set up to provide. There is a growing body of evidence suggesting that hybrid formats have the potential to improve student outcomes and reduce costs. ${ }^{3}$ The argument for hybrid courses can be made by pointing to shortcomings of both some traditional face-to-face courses and traditional online courses. With face-to-face courses, there is much excitement about the prospect of "flipping" courses to move lectures (content delivery) online and allow for more active learning and student engagement during class time. The high numbers of students enrolled in online courses - roughly three in ten college students takes at least one online course - also indicate a demand for more flexibility than traditional lecture-based courses provide.

But with online-only courses, studies show that some students - especially those most academically at risk - fare worse in terms of completion and outcomes, and that the gap between these students and other students actually expands in an online-only environment. In his new book, Higher Education in America, Derek Bok writes, "At present, therefore, only highly motivated, disciplined students seem to complete online courses with any regularity. It is not yet clear that such offerings can succeed in sustaining the interest and commitment of the legions of poorly prepared young people from mediocre high schools whom we will have to educate in order to lift our college graduation rates above their current, stagnant levels." It stands to reason that machine-guided learning, while potentially very valuable for certain applications, can only take students so far, and that teachers with personal knowledge of students are crucial to breathe life into these tools. ${ }^{5} \mathrm{~A}$ hypothesis we are eager to explore is whether solutions that combine the advantages of online formats - flexibility, efficiencies, data feedback-loops - with scaffolding and encouragement provided by face-toface instruction offer the best outcomes.

A number of MOOC creators have experimented with "flipping" their campus-based courses using their own MOOCs in hopes of improving student engagement and learning outcomes. These efforts begin to shed light on some of the questions raised above, but we would argue that this model is not widely replicable. First, the students participating in these experiments are enrolled in elite institutions (Princeton, Rice, Stanford) with very high completion rates. They are not representative of mainstream American students, and these institutions educate a relatively small portion of the student population. More to the point, it simply does not seem practical at a system-wide level for every professor to create her own MOOC or MOOC-like materials in order to "flip" her classes. The majority of instructors lack the time and resources, and such a scenario would surely result in widely uneven quality and student experience.

Thus a salient question is whether MOOCs can be used by professors other than those who created them to improve outcomes and lower costs for enrolled students. Over the past year a handful of experiments have begun to explore this possibility. San Jose State University ran a pilot supplementing an engineering course with a MOOC from MITx, and edX collaborated with community colleges to adapt an introductory computer science MOOC for use on their campuses. Douglas Fisher at Vanderbilt University offered a graduate seminar around a live offering of a machine learning MOOC from Coursera. ${ }^{6}$ San Jose State collaborated with Udacity to pilot three MOOCs for credit. These efforts are to be commended for trying 
...there are reasons

to be concerned

\section{about excessive}

reliance on a

small number

of commercial

providers and

proprietary control of

learning data... new things, especially those that shared their results publicly even when the results were less than rosy, and thus contributed to our common understanding of how these emerging technologies can be used successfully in traditional environments.

Another key question is what the level of need and demand is for resources to support this kind of model. In the Ithaka $S+R$ report "Barriers to Adoption of Online Learning Systems in US Higher Education," Larry Bacow noted "perhaps the largest obstacle to widespread adoption of ILO-style courses" is the lack of a "sustainable platform that allows interested faculty either to create a fully interactive, machine-guided learning environment or to customize a course that has been created by someone else (and thus claim it as their own)." 7 The Open Learning Initiative from Carnegie Mellon is a sophisticated prototype, but it is not easily customizable by instructors and has a limited range of content. Publishers such as Pearson and McGraw Hill have greatly expanded their online learning offerings and may be best positioned to provide such a service. But, however good these products are, there are reasons to be concerned about excessive reliance on a small number of commercial providers and proprietary control of learning data. New initiatives from within the academic community that have the potential to advance its values and interests would thus be a welcome addition to this rapidly evolving marketplace.

Are professors actively searching for such resources and frustrated by the options currently available to them? This level of demand is hard to gauge and very likely in flux. Through our partnership with the University System of Maryland, we have observed an impressive amount of innovation and experimentation with new teaching methods incorporating online tools. Then again, this system has been a leader in academic transformation and may not be representative of what is happening on campuses in other state systems. Surveys of faculty still show considerable skepticism of online learning and of MOOCs in particular. ${ }^{8}$ And such skepticism may be justified to a point given the dearth of rigorous evidence that these resources offer benefits for typical students and their teachers. Still, we expect that growing awareness of new instructional models, combined with pressure on administrators from trustees and regents to demonstrate progress on their campuses, will stimulate fairly dramatic growth in demand for new tools and content over the next decade.

At roughly the same time that the "Barriers" report was released, Coursera, edX, and Udacity launched in quick succession and instantly became the focus of public discourse on higher education, large financial investments, and the talents of some top computer scientists. These initiatives stimulated the creation of a large quantity of new content, some of which is very high quality, prompting us to ask the question of whether MOOCs could meet the need identified in the "Barriers" report. Another finding of that report was that adoption of new technologies will be severely constrained if instructors do not have the ability to customize courseware and "make the courses their own." Fortunately, the Coursera platform affords the flexibility to add, remove and reorder content so that instructors can customize the online materials for the needs of their courses. ${ }^{9}$ In all of our tests, local faculty members "own" their courses and determine how best to integrate the MOOC content.

Over the last ten months the faculty members at USM institutions have exceeded our hopes and come up with a wide variety of innovative ways to incorporate their chosen MOOCs. Some proposed to test whether they could use a MOOC to "flip" their courses without 


\section{A typical first}

generation MOOC is

an integrated bundle

of content, formative

and summative

assessments, social

collaboration, and

technology tools. having to create all the online lecture videos from scratch. A couple of instructors selected MOOCs focused on critical thinking and are weaving them into seemingly unrelated courses to strengthen students' analytical capacities in other subjects (for example, Studio Art). A member of a Psychology department designed a new program for incoming first year students around a MOOC on nutrition. The goal is to use the course content and activities to improve students' personal health habits - which have been shown to impact academic performance - in tandem with a course on Health in America. A political scientist is weaving a MOOC on "Generating the Wealth of Nations" into an introductory course on comparative politics to strengthen students' grasp of basic macroeconomic principles, thus deepening their understanding of the role that economics plays in shaping political systems (and vice versa).

Each of our partners has gone through a lengthy process to figure out how to work with MOOCs. To begin, they had to review all the content in the MOOC - watch each video, review each quiz and assignment, etc. At least one even enrolled in the live version of the MOOC in preparation for this study. They then had to try to match up the elements of the MOOC with their existing syllabus or develop a new syllabus around the MOOC. Some developed new videos, reading assignments, and assessments to supplement the MOOC materials. Most of our faculty partners found, once they delved into the planning process, that they needed to make more modifications than initially expected. It is clear that a substantial upfront investment is required, and we are working with the faculty to evaluate the magnitude of this investment and the type of work involved in preparing these courses.

Why not just take the MOOC as is and offer "wrap-around" instruction? It quickly became clear that we could not assume that a MOOC created at one institution meets the needs and standards of another. Some MOOCs were developed more for "lay" audiences and do not require the level of effort and rigor expected for a college-level course at our partner institutions. A couple of MOOCs seem to combine undergraduate and graduate level work. Any new course offering created around a MOOC would require approval from that institution's curricular committee, a process that was not feasible within the time frame of this project. If, on the other hand, a MOOC is embedded in an existing course, there needs to be a reasonably close match in terms of the approach to teaching the subject, the level of difficulty, the assumptions about students' prior knowledge, and the learning objectives. Finding this match turns out to be more difficult than one might imagine.

When USM and Ithaka $S+R$ staff presented the project to faculty, some expressed understandable skepticism. On one hand, there was generally a strong desire to have the ability to customize content. But on the other hand, when we explained that the instructors could select the MOOC content that best fit their courses, one faculty member queried how this model differs from simply assigning students to watch videos on YouTube. This answer really depends on how the MOOC is used. A typical first generation MOOC is an integrated bundle of content, formative and summative assessments, social collaboration, and technology tools. It has a narrative structure and certain coherency in the way that topics are presented and what knowledge and skills students are expected to develop. In addition, the interactive learning software and data analysis tools reinforce that coherence and add value for both the students and the teachers. The sum, therefore, is arguably more valuable than the parts. On the other side of this equation are a course and a curriculum tailored to an institution's students and programmatic goals. Bringing these two entities 


\section{A central question}

is whether one

can shave off the

corners of the peg

and retain enough of

its value to make this

exercise worthwhile together can seem very much like fitting a square peg into a round hole. A central question is whether one can shave off the corners of the peg and retain enough of its value to make this exercise worthwhile. There may be some threshold below which it is not worth the trouble of deconstructing a MOOC to pull out suitable elements. The variety of courses involved in the study should offer a better sense of this threshold, if it exists, and illuminate the general value of these tools in rebuilding a course.

We can be fairly sure that MOOCs will continue to evolve, and already the platform providers acknowledge the need for more modular, flexible course content that can be repurposed more easily. It is interesting to consider the evolution of Pearson's MyLabs, which started out as textbook supplements and are gradually growing to provide comprehensive content for entire courses. MOOCs started out with comprehensive courses but may well move towards provision of stackable modules. One wonders whether publisher and MOOC platform products and services will converge towards similar models or define distinctive approaches to serving institutions.

If we believe that there is (or will be) demand for MOOC content in hybrid formats, what are the prospects for supply? There seems to be ample interest among faculty members in creating MOOCs for the purpose of teaching large public audiences, and so far many of their host institutions are willing to bear the cost. It is less clear to what extent star professors will wish to create MOOC content that other instructors can repurpose. Several of the MOOC creators with whom we have corresponded are uneasy about allowing their MOOCs to be used by other instructors for different purposes and in different contexts. Some professors have raised concerns about licensing and/or compensation for the product they have produced. It has been suggested that MOOCs will become like multimedia textbooks in the future. But first generation MOOCs seem different from textbooks in the narrative structure and the personal connection that creators feel to this work product. For some, they may seem more like novels than textbooks; thus, the notion of having them broken into pieces and mixed with other content by unknown instructors at other institutions feels deeply disconcerting. We may see the emergence of two categories of MOOCs: one that follows the 2012 model of online courses taught synchronously to massive audiences, and a second category of content that deserves a different and more accurate appellation. Will star faculty be as motivated to create the second category of content as the first? It most likely involves considerably more work to design generic, interchangeable modules of content (consider that Pearson has probably invested millions of dollars developing the MyLabs suite of products). The motivations for doing so will depend, presumably, on the incentives available to faculty for this effort - and hence on the business models of the MOOC platform providers.

\section{How We Will Evaluate Results}

While the partnership with USM involves a great deal of "learning by doing," the evaluation of these tests is a crucial component of this initiative. Five of the tests are designed as side-byside comparisons in large, multi-section introductory courses. In these we are collecting data on the students' background characteristics, their course outcomes, and their experiences in the course in order to learn how different types of students fare in the hybrid sections compared to traditional, lecture-based sections. Designing such experiments was challenging due to the difficulty in matching MOOCs with existing courses such that common assessments could be used, and our reporting will disclose the pedagogical decisions made by instructors to bridge 
Even as we evaluate potential benefits of embedding MOOCs, it is critical to understand the upfront costs of these models and to try to gain some insight into potential longterm cost savings. these gaps. We are also conducting ten case studies, which are almost all hybrid formats, using MOOCs in single-section courses. For these tests we will collect the same types of data and look across courses for patterns, such as how particular subgroups of students fare, and implementation approaches that seemed to work particularly well or poorly.

Even as we evaluate potential benefits of embedding MOOCs, it is critical to understand the upfront costs of these models and to try to gain some insight into potential long-term cost savings. MOOCs and online education have also been proposed as potential solutions to the "cost disease" facing higher education. Some hope that by swapping out large lectures for MOOC lecture videos, instructors will have time to teach more sections. Others suggest that MOOCs will enable institutions to increase class sizes and thus enroll more students at the same cost. We are working with instructors and support staff to capture data on the time they spend developing and delivering the test courses in hopes of providing some insight to these hypotheses.

More detail about the methodologies we are using for the components of this initiative will be available in the interim report cited earlier.

\section{What About the Students?}

In the public discourse about MOOCs, it is striking how little is known about how mainstream students regard MOOCs - or even hybrid courses more broadly. This set of experiments will provide a valuable opportunity to gain some insight into what a diverse set of students think of this format. There are many questions we wish to explore. At the most basic level, how do students feel about being enrolled in hybrid courses in which they are required to watch lectures online? In one of our tests, a student enrolled in multiple hybrid courses complained to her instructor about having to watch hours of online videos and feeling as though she spends all of her time in front of a computer screen. The Interactive Learning Online at Public Universities: Evidence from Randomized Trials ${ }^{10}$ study found that students in hybrid sections had the same outcomes as those in traditional sections, but they enjoyed the course less. As the trend to "flip" classes takes off, how will increased reliance on online content delivery across a growing number of courses impact the overall student experience? It is crucial that academic transformation be coordinated across departments and programs, and not designed solely at the course level. William Bowen has argued for a "portfolio" approach to curricular design, in which students are encouraged or required to enroll in courses employing a mix of formats. ${ }^{11}$

Another question is what kinds of guidance are needed to help students succeed in hybrid courses, as we have heard from a number of sources that students need to be "re-trained" to take more responsibility for their learning. In a pilot study we conducted during the spring, instructors observed that students in the hybrid sections were falling behind. They quickly set about recalibrating students' expectations about their responsibilities in the course, providing a list of ten tips to be successful. These included pointers such as watching the online lectures as part of a daily routine, not trying to sit down and watch a week's worth of lecture videos in one sitting, and so on. At the conclusion of the course, there were no significant differences in outcomes between the hybrid and traditional sections, which had considerably more class time. In another of our tests, the MOOC is used both for the educational content and as a vehicle to teach first year students how to do online learning. Students watch videos together during class time and then discuss methods of taking notes and absorbing important concepts. 


\section{Even less is known}

\section{with regard to the} use of MOOCs in

\section{hybrid courses}

taught by an

instructor other than

the MOOC creator:

\section{What is it like being}

taught by two lead

instructors?
Even less is known with regard to the use of MOOCs in hybrid courses taught by an instructor other than the MOOC creator: What is it like being taught by two lead instructors? How do students respond to course materials created by a MOOC creator versus. publisher content? In a graduate seminar at Vanderbilt taught around a MOOC, students responded positively to the MOOC but felt that it was not well aligned with the face-to-face component. ${ }^{12}$ To explore these questions we are collecting two types of data. First, we are conducting end-ofsemester surveys across all twenty-two tests, enabling us to compare the student experience in hybrid versus traditional sections, and also to compare the student experience in hybrid sections using different technology platforms (MOOCs, OLI, and Pearson MyLabs). Second, we will conduct a targeted set of interviews or focus groups with students to deepen our understanding of their experiences.

\section{Where We Are Now, What We Hope to Learn}

Although we have already learned an enormous amount about the opportunities and challenges associated with implementing MOOCs in campus settings, most of the tests are just getting started. The assessment of these tests will be crucial in providing an objective view of how students fare, and these findings will be reported in spring of 2014. We hope to provide policy-makers, administrators, and faculty who view MOOCs with an open but cautious eye with some carefully-collected and analyzed data upon which to base future decisions. We hope to provide MOOC platforms and their partners with input on the needs of institutional users and how this market differs from serving students directly. And, if we are very fortunate, perhaps we can suggest a new terminology that better reflects the ways in which these materials can benefit enrolled students. 


\section{END NOTES}

1 See Steve Kolowich, “The MOOC Survivors," InsideHigherEd, September 12, 2012, and "Who Takes MOOCs?" InsideHigherEd, June 5, 2012, all accessed on September 24, 2013. According to Kolowich, of 8,000 students who enrolled in the first offering of MITx's Circuits and Electronics course and responded to a survey, $70 \%$ of students had a Bachelor's degree or higher. Additionally, surveys from Coursera and Udacity found that the majority of their users were working professionals and graduate students, and Coursera reported that $74 \%$ of its students were international. Udacity also said that "the vast majority" of its students were from outside the US

2 Interested readers can also review our interim report, "A Collaborative Effort to Test MOOCs and other Online Learning Platforms on Campuses of the University System of Maryland," which provides more detail about the project, the methodology of the main components, and what we have learned so far about opportunities and challenges associated with embedding MOOCs in campus-based settings. http://sr.ithaka.org/research-publications/informinginnovation-higher-education-evidence-implementing-latest-online.

3 See William G. Bowen, Matthew M. Chingos, Kelly A. Lack, and Thomas I. Nygren. Interactive Learning Online at Public Universities: Evidence from Randomized Trials. Ithaka S+R. May 22, 2012. See also Carol A. Twigg, "New Models for Online Learning: Improving Learning and Reducing Costs," Educause (September-October 2003 ), p. 28.

4 See Derek Bok, Higher Education in America, Princeton University Press, 2013. p 151.

5 See Di Xu and Shanna Smith Jaggars, "Adaptability to Online Learning: Differences Across Types of Students and Academic Subject Areas," February 2013, CCRC Working Paper No. 54. See also Barbara Means, Yukie Toyama, Robert Murphy, Marianna Murphy, Marianne Bakia, and Karla Jones, "Evaluation of Evidence-Based Practices in Online Learning: A Meta-Analysis and Review of Online Learning Studies," U.S. Department of Education, Revised September 2010. See also Rob Firmin, Eva Schiorring, John Mitmer, and Terrence Willett, and Sutee Sujitparapitaya, "Preliminary Summary: SJSU+ Augmented Online Learning Environment Pilot Project," September 2013.

6 See Derek O. Bruff, Douglas H. Fisher, Kathryn E. McEwen, and Blaine E. Smith, "Wrapping a MOOC: Student Perceptions of an Experiment in Blended Learning," Journal of Online Teaching and Learning, Vol. 9, No. 2, March 2013, page 187.

7 See Lawrence S. Bacow, William G. Bowen, Kevin M. Guthrie, Kelly A. Lack, and Matthew P. Long, "Barriers to Adoption of Online Learning Systems in U.S. Higher Education," May 1, 2012, p. 16. Available on the ITHAKA website: http://www.sr.ithaka.org.

8 See Elaine Allen and Jeff $\neg$ Seaman with Doug Lederman and Scott Jaschik, “Conflicted: Faculty and Online Education 2012," Inside Higher Ed and Babson Survey Research Group.

9 Technically they also have the ability to modify assessments and assignments, but modification of existing content raises important IP issues that are yet to be resolved. 10 See William G. Bowen, Matthew M. Chingos, Kelly A. Lack, and Thomas I. Nygren. Interactive Learning Online at Public Universities: Evidence from Randomized Trials. Ithaka S+R. May 22, 2012.

11 See William G. Bowen, Higher Education in the Digital Age, Princeton University Press, 2013.

12 See Derek O. Bruff, Douglas H. Fisher, Kathryn E. McEwen, and Blaine E. Smith, "Wrapping a MOOC: Student Perceptions of an Experiment in Blended Learning," Journal of Online Learning and Teaching, Vol 9, No. 2, June 2013. 